Paper ID \#19868

\title{
Design-based Research and Soft Robotics to Broaden the STEM Pipeline (Work in Progress)
}

\section{Mr. Andrew Jackson, Purdue Polytechnic Institute}

Andrew Jackson is currently pursuing a PhD in Technology through Purdue's Polytechnic Institute, with an emphasis on Engineering and Technology Teacher Education. His research interests are engineering self-efficacy, motivation, and decision making. Andrew is the recipient of a 2015 Ross Fellowship from Purdue University and has been recognized as a 21st Century Fellow by the International Technology and Engineering Educators Association. He completed his Master of Science in Technology Leadership and Innovation at Purdue University with a thesis investigating middle school engineering self-efficacy beliefs. He previously taught middle school and undergraduate technology courses, accompanying both experiences with classroom research to improve practice.

\section{Mr. Jiawei Zhang, Purdue University}

Jiawei Zhang is a Master's student in Mechanical Engineering at Purdue University focusing on robotics and design. Prior to joining the Faboratory at Purdue University, he obtained a Bachelor of Science degree in Mechanical Engineering from North Dakota State University. He is a problem solver with strong handson skills and industrial experience. Currently, he is working on the characterization and fabrication of soft robotic grippers.

\section{Prof. Rebecca Kramer, Purdue University}

Rebecca Kramer is an Assistant Professor of Mechanical Engineering at Purdue University. She holds the degrees of B.S. from Johns Hopkins University, M.S. from the University of California at Berkeley, and Ph.D. from Harvard University. Her lab, the Faboratory, contains a leading facility for the rapid design, fabrication, and analysis of materially soft and multifunctional systems. Her research expertise is in stretchable electronics, responsive material actuators, soft material manufacturing, and soft-bodied control. Dr. Kramer serves as an Associate Editor and Editorial Board member of Frontiers in Robotics and AI: Soft Robotics. She is the recipient of the NSF CAREER Award, the NASA Early Career Faculty Award, the AFOSR Young Investigator Award, the ONR Young Investigator Award, and was named to the 2015 Forbes 30 under 30 list.

\section{Prof. Nathan Mentzer, Purdue University}

Nathan Mentzer is an assistant professor in the College of Technology with a joint appointment in the College of Education at Purdue University. Hired as a part of the strategic P12 STEM initiative, he prepares Engineering/Technology candidates for teacher licensure. Dr. Mentzer's educational efforts in pedagogical content knowledge are guided by a research theme centered in student learning of engineering design thinking on the secondary level. Nathan was a former middle and high school technology educator in Montana prior to pursuing a doctoral degree. He was a National Center for Engineering and Technology Education (NCETE) Fellow at Utah State University while pursuing a Ph.D. in Curriculum and Instruction. After graduation he completed a one year appointment with the Center as a postdoctoral researcher. 


\section{Design-Based Research and Soft Robotics to Broaden the STEM Pipeline (Work In Progress)}

This report describes the intent, methods, and progress of the three-year NSF award "Soft Robotics to Broaden the STEM Pipeline," which is a partnership between Purdue University, high-school teachers and the curriculum provider Engineering byDesign (EbD). Our work presents an integration of novel curriculum materials - soft robotics, in contrast to traditional robotics - and methods - design-based research - to shed light on high-school student STEM perceptions and how instructional design can be leveraged to affect those perceptions. We are nearing completion of year two of the project, and are able to share findings relevant to ASEE's Precollege Engineering Education Division including lessons learned from the application of design-based research methods; the present state of our curriculum materials; and preliminary findings regarding changes in student STEM motivation, self-efficacy, and interest in the context of the curriculum experience.

\section{Novel Approach to Robotics in Education}

Robotics content can support a host of educational outcomes including electronics, programming, problem-solving, and design thinking ${ }^{1}$. The growing number of robotics tools further enables their use for education: Arduino, Raspberry Pi, LEGO Mindstorms, Fischertechniks, and new crowd-funded options are surrounded by educational tutorials and content. In general, robotics activities are diverse and provide solutions to many instructional needs. Soft robots are made from soft, deformable gels, liquids, or polymers ${ }^{2}$ and represent an emerging type of robotics design. We believe soft robotics may enhance student interest and confidence for STEM to a greater degree than traditional "hard" robotics, made from wood or metal components.

Changing student perceptions is challenging. Evidence suggests that many robotics programs (whether curricular or extra-curricular) do little to increase interest or decrease gender gaps in STEM. An evaluation of FIRST, a robotics design and build competition for high school students, showed fewer than $30 \%$ of participants were female with male and female participants taking different roles in the project; young men were more likely to be involved in the design, assembly, and programming, with young women taking on marketing and fundraising, community service, and communications responsibilities ${ }^{3}$. Another study by Hartmann, Wiesner, and Wiesner-Steiner ${ }^{4}$ noted that for traditional robotics design "the materiality of the robotics itself plays an important role here, i.e. the fact that it already comes along as gendered material" (p. 175) and recommended "deconstruct[ing] gendered material right from the beginning" (p. 187) to ensure equal advantage from the curriculum. Indeed, these gendered effects are noticeable in the proportion of Bachelor's degrees awarded to female students ${ }^{5}$. Traditional robotics draws heavily from the fields of mechanical engineering, electrical engineering, and computer science; these areas have had a historically low percentage of degrees awarded for females - only $11.7 \%, 11.5 \%$, and $11.2 \%$ respectively.

On the other hand, the growing field of soft robotics tends towards disciplines including biomedical engineering, biological and agricultural engineering, chemical engineering, and materials engineering which have had proportionally higher female participation-39.1\%, $31.9 \%, 33.1 \%$ and $28.4 \%$ respectively. Soft robots are often bio-inspired (connecting to 
biomedical engineering and biological and agricultural engineering) and rely on chemical reactions and material properties to move (chemical and materials engineering, respectively). They are composed of squishy, non-rigid components, such as silicone rubber and fabric, which can support new properties for robotics applications ${ }^{6}$. These are materially soft and safe for human interaction, making intuitive connections to human-robot interactive applications. The variety of fabrication materials may help disentangle robotics design and fabrication from gender stereotypes, thus encouraging female involvement. The potential of soft robot design to address important factors such as the societal relevance of engineering (based on the human-robot interaction), and tinkering and technical self-efficacy of female students (based on the material), invites the development and analysis of soft robot curriculum experiences such as ours. Example research and applications of soft robots are shown in Figure 1.

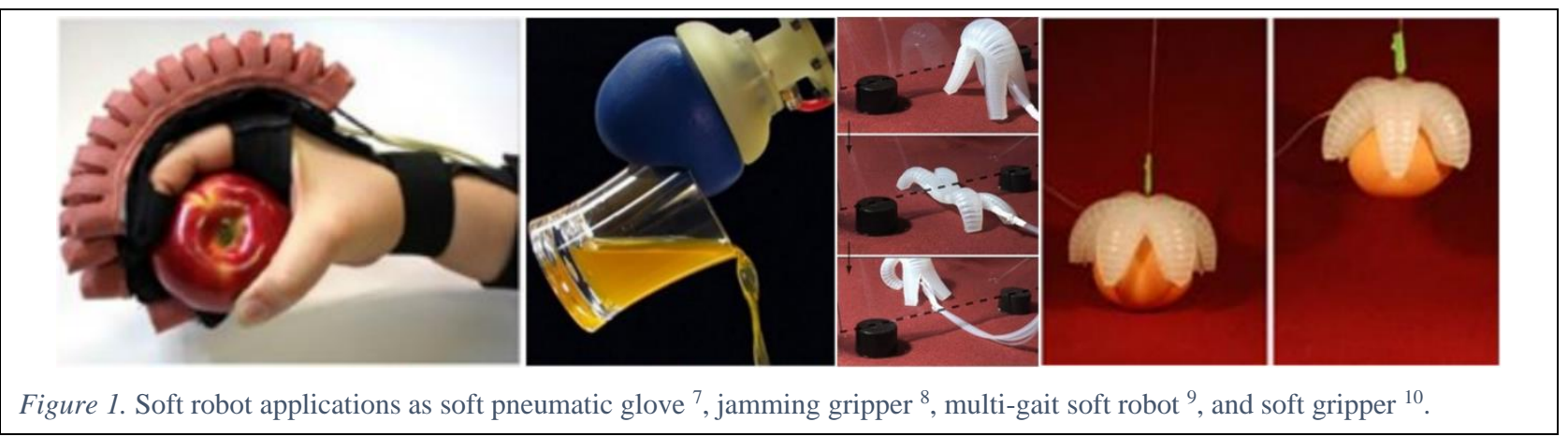

\section{Novel Methods for Research}

The "Soft Robotics to Broaden the STEM Pipeline" project to implement soft robotics in the high-school curriculum has used design-based research (DBR) methods to facilitate instructional design and evaluation. DBR parallels principles of design as we teach them in our technology and engineering classes: "Design has its own distinct 'things to know, ways of knowing them, and ways of finding out about them" so it investigates "the man-made world" through "modelling, pattern-formation, [and] synthesis" toward values of "practicality, ingenuity, empathy, and a concern for "appropriateness"' (p. 221-222) ${ }^{11}$. DBR leverages the complexity of educational environments; opportunities for iteration in different contexts (to see what works, when); and product-based nature of curriculum design. We have partnered with Engineering byDesign (EbD), a K12 engineering curriculum provider, and seven high-school teachers in rural and suburban Mid-Atlantic schools, for access to an authentic educational environment and to extend robotics offerings in their curriculum.

In DBR, researchers "systemically adjust various aspects of the designed context so that each adjustment [serves] as a type of experimentation" (p. 3) ${ }^{12}$. Throughout research phases, the procedures can be modified (in contrast to traditional psychological experiments which have rigid procedures to isolate variables). At this stage of the research project incoming data and ongoing experiences allow the soft robot design experience to be "constantly revised...until all the bugs are worked out" (p. 18) ${ }^{13}$. Thus, throughout the curriculum's development and implementation, we are varying the conditions of our investigation in an effort to see what works best. Student formative evaluations, survey responses and engineering notebooks; teacher interviews; and classroom observations provide a lens on the soft robot design experiment and inform our iteration with the materials and processes. 
Presently, teachers are in the midst of delivering the soft robot experience-some will conduct it multiple times during the year depending on the semester structure of their classes. This frequent repetition has allowed us to gather feedback on the experience and make recommendations prior to the next iteration, the next time teachers deliver the content. The guiding research question of our study is "Will the implementation of design experiences with soft robots improve engineering self-efficacy and motivation as compared to design experiences with traditional robots, particularly among high school females?" Therefore, changes in the developing curriculum should be made to enhance STEM self-efficacy, motivation, and interest as they coincide with participation in the soft robot experience.

\section{Past, Present, and Future Efforts of the Project}

The following sections describe our team's efforts to develop and implement the soft robot design experience, in partnership with practitioners. Annual project aims are alternated with findings and descriptions.

\section{Year 1 - Initial Curriculum Development}

In terms of curriculum development, we began with standards and learning objectives from the traditional robotics lesson included in EbD's ninth-grade Foundations of Technology curriculum. These include aspects of the Standards for Technological Literacy (STL) ${ }^{14}$ and Next Generation Science Standards (NGSS) ${ }^{15}$ such as "Students will develop abilities to apply the design process" (STL 11) and "Design a solution to a complex real-world problem by braking it down into smaller, more manageable problems that can be solved through engineering" (NGSS ETS1-2). The instruction and design activity emphasize documentation, iteration, and communication of design ideas. Over the approximately two-week experience students learn about pneumatic actuation. Students are then expected to apply this scientific knowledge to design, fabricate, and demonstrate a robotic gripper that can be used to pick up and place objects. Changes in the curriculum are described further below.

Beyond curriculum, the initial focus of the project was feasibility and usability of the curriculum. Our adapted process involved two dimensions: adapting from step-by-step procedures previously used in an outreach setting ${ }^{16}$ to a two-week design experience, and adapting from laboratory control and equipment to the unpredictability and budget of classroom settings. We internally developed and tested various 3D printed mold designs to support design flexibility (see Figure 2 and Zhang, Jackson, Hacker, Mentzer, and $\operatorname{Kramer}^{17}$ ). For example, the mold parts afford variation in the length of the gripper, configuration of internal pneumatic chambers, and different fill heights to affect the elasticity of the robot (see Figure 3). Mold iterations reduced the amount of silicone leaking from the mold when curing which lead to a larger proportion of successful robots. We also refined instructions on the process by adding details; this reduced the occurrence of gripper build problems. Another challenge involved finding processes that would work for high school block classes (about 90 minutes long) or regular classes (about 45 minutes). We tested commonly available "incubators" - toaster ovens — which would be accessible and affordable for K12 engineering. 

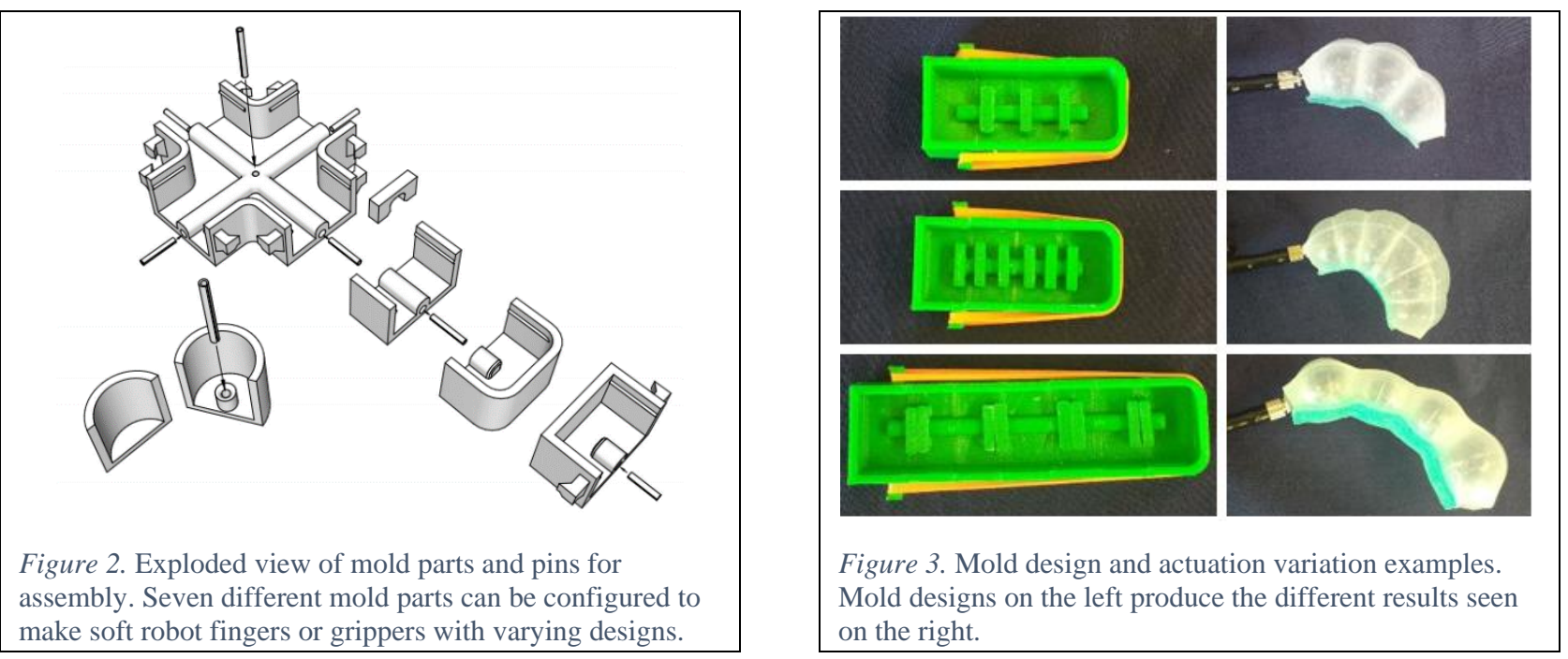

We needed to test fabrication materials and steps in classroom contexts since the processes were adapted from research laboratory settings. This was done through several pilot tests with 1) an undergraduate engineering and technology teacher education course at Purdue University, 2) a local afterschool program, 3) our own families, 4) a local high-school technology classroom, and 5) a summer camp program where the soft robot experience was implemented. The year culminated with leading a teacher professional development experience for partner teachers who would implement in the fall.

\section{Soft Robot Design Experience}

For the final version of the soft robot lesson we decided to engage students with a design-based challenge framed in the social context of helping a small farm operation by designing a robot gripper. Students complete the design challenge by making several iterations of soft robot fingers to explore the functionality and different design outcomes of the pneumatically actuated fingers. The fabrication process leverages the enhanced, modular mold design which evolved in our work. The design allows design flexibility where students can make a finger or entire gripper or change the design configuration leading to a different curving motion of the robot. Following testing and data collection, students can make informed gripper design solution for the final criteria of sorting produce goods. Overall, students make at least three rounds of finger and gripper designs which allow them to refine both the manufacturing steps and the design. The project culminates in student presentations on the design and demonstration of the gripper.

\section{Year 2 - Implementation and Project Refinement}

The second year of our project has allowed us to see implementation and preliminary data collection on the soft robot design experience. Seven teachers have been recruited to participate in the project and were shown the soft robot materials as part of the summer professional development training in year 1 . Year 2 data collection efforts have focused on feasibility and usability of the soft robot materials for student success in fabrication. We have also collected initial measurement of participating student STEM motivation (using the Situational Motivation Scale; Guay, Vallerand, and Blanchard ${ }^{18}$ ), self-efficacy (using the General Engineering SelfEfficacy and Engineering Skills Self-Efficacy Scales; Mamaril, Usher, Li, Economy, and 
Kennedy ${ }^{19}$ ), and interest (using a subscale of the STEM Career Interest Survey; Kier, Blanchard, Osborne, and Albert ${ }^{20}$ ) and samples of student design work. Teachers have reported problems and been able to co-develop the curriculum materials with us in preparation for final improvements to the curriculum. Participating teachers have continued to teach a traditional robotics curriculum with some classes so we are afforded a comparison between the hard and soft robot design experiences.

\section{Preliminary Findings}

The soft robot curriculum seems feasible for implementation based on classroom observations and teacher feedback. The modular mold has afforded design variation. Students and teachers seem engaged with the material and have been able to create soft robot grippers, though we are working to improve the success rate for student designs. Those interested can find the current curriculum and mold materials online at http://tiny.cc/SRMolds.

Quantitative survey data from the first round of delivery has been recorded, with student responses before and after the curriculum matched. Based on teacher's first implementation there were not observed effects on student motivation for $\mathrm{STEM}^{21}$. A change in student engineering self-efficacy following participation in the curriculum was evidence that represents a starting place for affecting student perceptions. Among 169 student responses with matched pre- and post-survey data to date, students in the soft robotics curriculum showed an increase in their selfefficacy while students in the traditional robotics curriculum did not, $F(1,165)=3.78, p=.05$. No gender effects have been observed at this point of our analysis and other survey results (e.g., STEM interest or design self-efficacy) have not yet been analyzed. We anticipate further responses to the survey and hope to identify more factors of the classroom experience that raise student attitudes.

\section{Year 3 - Future Implementation and Evaluation}

Efforts of our soft robot design project are moving toward a refined curriculum and implementation experience. The upcoming experience will present an opportunity for further iteration toward greater female interest in STEM by participating in the experience; it will also be an opportunity to investigate deep reasons behind changing perceptions. Data collection will include student surveys on STEM motivation, self-efficacy, and interest, as well as observations and interviews to better understand features of the soft robot experience that change student perceptions.

\section{Conclusion}

The DBR implementation of our soft robot experience has led to the development of curriculum materials and procedures, propagation of engineering research content to high school classrooms, and initial findings on student perceptions toward STEM. The flexibility of DBR affords us the chance to change our curriculum, making improvements based on teacher and student feedback; we will continue to do so, analyzing forthcoming results to gauge the success of the curriculum in changing student perceptions. The continuation of the project presents further opportunities to immerse ourselves in student design experiences and uncover features that are influential for changing student perceptions about engineering. 


\section{Acknowledgements}

This materials is based upon work supported by the National Science Foundation under Grant No. 1513175-DRL.

\section{References}

1. McGrath, E., Sayres, J., Lowes, S., \& Lin, P. (2008, October). Underwater lego robotics as the vehicle to engage students in STEM: The build it project's first year of classroom implementation. Paper presented at the American Society for Engineering Education Middle Atlantic Section Fall Conference, Hoboken, NJ.

2. Majidi, C. (2013). Soft robotics: A perspective-current trends and prospects for the future. Soft Robotics, 1(1), 5-11. doi: 10.1089/soro.2013.0001

3. Center for Youth and Communities. (2011). Cross-program evaluation of the first tech challenge and the first robotics competiton. Waltham, MA: Heller School for Social Policy and Management, Brandeis University.

4. Hartmann, S., Wiesner, H., \& Wiesner-Steiner, A. (2007). Robotics and gender: The use of robotics for the empowerment of girls in the classroom. In I. Zorn, S. Maass, E. Rommes, C. Schirmer \& H. Schelhowe (Eds.), Gender designs it: Construction and deconstruction of information society technology (pp. 175-188). Wiesbaden, Germany: VS Verlag für Sozialwissenschaften.

5. Yoder, B. L. (2014). Engineering by the numbers. Retrieved from: https://www.asee.org/papers-and-publications/publications/14_11-47.pdf

6. Trimmer, B. (2013). A journal of soft robotics: Why now? Soft Robotics, 1(1), 1-4. doi: 10.1089/soro.2013.0003

7. Polygerinos, P., Lyne, S., Wang, Z., Nicolini, L. F., Mosadegh, B., Whitesides, G. M., \& Walsh, C. J. (2013). Towards a soft pneumatic glove for hand rehabilitation. Paper presented at the 2013 IEEE/RSJ International Conference on Intelligent Robots and Systems (IROS), Tokyo, Japan.

8. Brown, E., Rodenberg, N., Amend, J., Mozeika, A., Steltz, E., Zakin, M. R., . . J Jaeger, H. M. (2010). Universal robotic gripper based on the jamming of granular material. Proceedings of the National Academy of Sciences, 107(44), 18809-18814.

9. Shepherd, R. F., Ilievski, F., Choi, W., Morin, S. A., Stokes, A. A., Mazzeo, A. D., . . Whitesides, G. M. (2011). Multigait soft robot. Proceedings of the National Academy of Sciences, 108(51), 20400-20403.

10. Ilievski, F., Mazzeo, A. D., Shepherd, R. F., Chen, X., \& Whitesides, G. M. (2011). Soft robotics for chemists. Angewandte Chemie, 123(8), 1930-1935.

11. Cross, N. (1982). Designerly ways of knowing. Design Studies, 3(4), 221-227. doi: 10.1016/0142-694X(82)90040-0

12. Barab, S., \& Squire, K. (2004). Design-based research: Putting a stake in the ground. Journal of the Learning Sciences, 13(1), 1-14. doi: 10.1207/s15327809j1s1301_1

13. Collins, A., Joseph, D., \& Bielaczyc, K. (2004). Design research: Theoretical and methodological issues. Journal of the Learning Sciences, 13(1), 15-42. doi: 10.1207/s15327809j1s1301_2 
14. International Technology Education Association, \& Technology for All Americans Project. (2007). Standards for technological literacy: Content for the study of technology (3rd ed.). Reston, VA: International Technology Education Association. (Original work published 2000)

15. NGSS Lead States. (2013). Next generation science standards: For states, by states. Washington, DC: National Academies Press.

16. Finio, B., Shepherd, R., \& Lipson, H. (2013, March 2013). Air-powered soft robots for K12 classrooms. Paper presented at the IEEE Integrated STEM Education Conference (ISEC), 2013. doi:10.1109/ISECon.2013.6525198

17. Zhang, J., Jackson, A., Hacker, S., Mentzer, N., \& Kramer, R. (2017). A modular, reconfigurable mold for a K-12 soft robotic gripper activity. Manuscript in preparation.

18. Guay, F., Vallerand, R. J., \& Blanchard, C. (2000). On the assessment of situational intrinsic and extrinsic motivation: The situational motivation scale (SIMS). Motivation \& Emotion, 24(3), 175-213.

19. Mamaril, N. A., Usher, E. L., Li, C. R., Economy, D. R., \& Kennedy, M. S. (2016). Measuring undergraduate students' engineering self-efficacy: A validation study. Journal of Engineering Education, 105(2), 366-395. doi: 10.1002/jee.20121

20. Kier, M. W., Blanchard, M. R., Osborne, J. W., \& Albert, J. L. (2013). The development of the STEM career interest survey (STEM-CIS). Research in Science Education, 44(3), 461-481. doi: 10.1007/s11165-013-9389-3

21. Jackson, A., Mentzer, N., Kramer, R., \& Zhang, J. (2017, June). Enhancing student motivation and efficacy through soft robot design. Paper presented at the 2017 ASEE Annual Conference \& Exposition, Columbus, $\mathrm{OH}$. 